\title{
MODEL KONWOJU JAKO SKUTECZNY MECHANIZM TRANSFERU WIEDZY Z GNIAZD INNOWACJI DO GOSPODARKI POLSKI
}

https://doi.org/10.33141/po.2019.05.03

\section{Wojciech Rokosz}

\section{Wprowadzenie}

$\mathrm{T}$ ematyka konkurencyjności gospodarki stanowi istotny obszar badawczy dla wielu ekonomistów. Wynika to $\mathrm{z}$ faktu, iż zdolność do wdrażania nowych, lepszych rozwiązań opartych na wiedzy jest kluczowa dla wzrostu gospodarczego, tym samym powodując zasadniczą poprawę zamożności społeczeństw (Atkinson, Ezell, 2012, s. 9). Polska należy do najmniej innowacyjnych krajów UE (European Innovation Scoreboard, 2017, s. 9), co - jeśli nic się w tej kwestii nie zmieni - może powodować rosnące problemy ekonomiczne i społeczne (tzw. pułapka średniego dochodu).

Innowacje zazwyczaj powstają $\mathrm{w}$ ramach systemów innowacji, gromadzących różnych uczestników tych procesów, m.in. uczelnie, firmy, organizacje rządowe czy instytucje finansowe (Lundvall, 1992, s. 12). Innowacyjność państw i regionów warunkowana jest wieloma czynnikami, które można ująć na przykład modelem 3T (Florida, 2004, s. 228), tj. technologią (infrastruktura technologiczna, dostęp do zasobów), talentem (kapitał ludzki) i tolerancją (kultura otwarta na nowości, wyższa skłonność do ryzyka). $\mathrm{W}$ związku z tym zyskują państwa i regiony umiejące efektywnie posługiwać się powyższymi czynnikami, tzw. technopolie (Saxenian, 1994, s. 45) - przykładami takich miejsc są choćby Dolina Krzemowa czy Izrael.

W ostatnich latach dużo działań i zasobów zostało ukierunkowanych na poprawienie czynników innowacyjności w UE, w tym w Polsce. Poprawa ekosystemu jest bardzo ważnym kierunkiem działań i konieczne są inwestycje w tym obszarze, niemniej jednak rozwój ekosystemu wymaga dekad systematycznych inwestycji, a ich sukces nie jest pewny, zależy bowiem od wielu czynników (Weresa, 2012, s. 12-16). Analizując uwarunkowania innowacyjności, warto zatem rozważyć, czy istnieją również inne sposoby na poprawienie konkurencyjności danej gospodarki, w warunkach odbiegających od tych spotykanych $\mathrm{w}$ technopoliach, tzn. przy ograniczonych czynnikach innowacyjności. I jeśli tak, to jakie. W kontekście krajów i regionów o niższym poziomie rozwinięcia systemu innowacji na znaczeniu zyskują rozwiązania instytucjonalne, które często pozwalają pokonywać wymienione ograniczenia szybciej i przy znacząco niższych nakładach. Ciekawym sposobem na zwiększanie konkurencyjności peryferii jest prowadzenie programów akceleracyjnych dla firm poprzez internacjonalizację w technopoliach, np. w Dolinie Krzemowej (Bitka i in., 2017, s. 5-12; Bitka i in., 2018, s. 7-14).
Przegląd Organizacji, Nr 5 (952), 2019, ss. 16-25 www.przegladorganizacji.pl (cTowarzystwo Naukowe Organizacji i Kierownictwa (TNOiK)
Niemniej jednak jednym z najistotniejszych rozwiązań instytucjonalnych, na jakie badacze zwracają uwagę, są powiązania sieciowe między organizmami gospodarczymi powodujące szereg pozytywnych efektów (np. knowledge spillovers, efekty skali) dla rozwoju gospodarczego (Granovetter, 1983, s. 219). Architektura owych powiązań sieciowych i aliansów strategicznych może się jednak zasadniczo różnić $\mathrm{w}$ zależności od specyfiki danego państwa czy regionu. Doświadczenia wielu krajów pokazują, że w warunkach gospodarek, które dysponują ograniczonymi zasobami czynników innowacyjności, budowanie narzędzi wsparcia powiązań kooperacyjnych celem usprawnienia procesu transferu wiedzy do gospodarki w oparciu o klasyczne koncepcje powiązań kooperacyjnych, np. klastry (Porter 1990), jest mniej skuteczne niż w przypadku krajów z wysokimi zasobami innowacyjnymi (Fitjar, Rodriguez-Pose, 2011, s. 3). Jednym z modeli proponowanych do zastosowania $\mathrm{w}$ tych warunkach jest model konwoju (Mensch, Bertolin, 2010), odwołujący się do teorii biegunów wzrostu Perroux, przez koncepcje firmy flagowej (flagship company) czy czempionów narodowych. Powtarzającą się w powyższych modelach myślą jest specyficzna architektura powiązań oparta na istnieniu firmy bądź instytucji, wokół której organizowana jest sieć współpracujących firm.

$\mathrm{W}$ prezentowanej pracy podjęto badania istniejących powiązań na linii polskie korporacje - startupy, aby odpowiedzieć na pytanie, czy w warunkach polskich zastosowanie modelu konwoju byłoby możliwe oraz czy polskie korporacje są gotowe pełnić rolę lokomotyw zdefiniowanych w tym modelu poprzez dedykowanie odpowiednich zasobów (ludzkich i finansowych) oraz budowę skutecznych powiązań między centralną działalnością biznesową a innowacjami pochodzącymi z zewnątrz. Wnioski z przeprowadzonych badań posłużą do przedstawienia zarysu rekomendacji w obszarze współpracy korporacji i startupów, które mogą przyczynić się do umocnienia działań w tym obszarze oraz wzrostu zaangażowania polskich firm w działalność innowacyjną.

Artykuł podzielony jest na cztery części. Wprowadzenie prezentuje cel publikacji, pytania badawcze oraz uzasadnienie podjęcia tematu. Przegląd literatury wprowadza bardziej szczegółowo w podjętą tematykę oraz pozycjonuje model konwoju w kontekście szerszej literatury dotyczącej współpracy korporacji ze startupami. Metoda 
badawcza przedstawia przyjętą metodykę pracy naukowej. Następnie opisane są wyniki badań, prezentujące uwarunkowania polskiego systemu innowacyjności oraz działania wybranych korporacji w obszarze innowacyjności i współpracy ze startupami. W ostatniej sekcji artykułu zaprezentowane są wnioski dla polityki i praktyki gospodarczej wraz z zarysem nowego modelu usprawnienia współpracy korporacji i startupów ${ }^{\mathbf{1}}$.

\section{Przegląd literatury - model konwoju a inne formy współpracy startupów i korporacji}

$M$ odel konwoju został stworzony przez G. Mensha i J.A. Bertolina (2010) w odpowiedzi na nieskuteczność funkcjonowania klasycznych klastrów w rozumieniu M.E. Portera w regionach o niskich zasobach sprzyjających rozwojowi przedsiębiorczości innowacyjnej. W szczególności mowa tutaj o ograniczonym dostępie do odpowiedniej infrastruktury, wykwalifikowanych kadr oraz niesprzyjającej kultury w modelu 3T Floridy (Florida, 2004, s. 228). Główną różnicą między klasycznym klastrem a zgrupowaniem firm w modelu konwoju jest to, że w modelu konwoju sieć firm kształtuje się wokół centralnej firmy bądź instytucji, w przeciwieństwie do klasycznego modelu, w którym klaster definiowany jest jako stosunkowo chaotyczne i równomierne zgrupowanie firm. Zasadniczym elementem klastrów w modelu konwoju jest tzw. lokomotywa, tj. lider w danej sieci, który uzupełnia braki wśród firm z otoczenia w obszarze wymienionych wcześniej czynników stanowiących o ich innowacyjności; głównie są to zasoby, wiedza, dostęp do sieci, infrastruktura.

Model konwoju jest nowym podejściem do problemu wzrostu konkurencyjności w regionie i stanowi próbę rozwoju i ulepszenia teorii klastrów. Po pierwsze, konwój w odróżnieniu od klasycznego klastra jest obiektem dynamicznym. Dynamikę jego działaniom nadaje „lokomotywa”, czyli stabilna centralna firma lub instytucja, dynamizująca działania wewnątrz. Istotnym elementem jest wychodząca od środka inicjatywa do powstania nowych firm, która przyśpiesza rozwój i tempo wzrostu całości systemu. Po drugie, konwój jest mniej chaotyczny. Centralna instytucja harmonizuje działania wszystkich firm oraz stara się ciągnąć całe ugrupowanie ku wyznaczonym dalekosiężnym celom, które przy ograniczonych zasobach małych firm działających samodzielnie często nie są nawet formułowane.

W praktyce gospodarczej można znaleźć podobieństwa między teorią modelu konwoju oraz organizacją działalności gospodarczej, która miała miejsce np. w Japonii czy Korei. Mowa tutaj o japońskich „Zaibatsu” i powojennych „Kairetsu” oraz koreańskich firmach „Chaebol” - dużych, wiodących firmach o wartości strategicznej, wspieranych przez rząd. Dużo podobieństw można również znaleźć w niemieckich koncepcjach organizacji gospodarki z wiodącą rolą dużych międzynarodowych korporacji.

Naukowcy już od dawna postulowali, iż na rynkach konkurencyjnych firmy muszą wdrażać innowacyjne produkty i usługi w celu utrzymania zyskowności (Schum- peter, 1939). Niemniej jednak, pomimo tej ekonomicznej konieczności, wielu badaczy podkreśla ograniczone możliwości generowania innowacji, a tym bardziej radykalnych innowacji, wewnątrz już funkcjonujących na rynkach firm (Henderson, 1993, s. 248). Aby przezwyciężyć te ograniczenia, firmy mogą starać się wykorzystywać wiedzę z zewnątrz. Potencjalne źródła wiedzy, tzw. gniazda innowacji, obejmują sieci pracowników i firm (Saxenian, 1990, s. 91; Laursen, Salter, 2006, s. 146-148), laboratoria i instytuty akademickie oraz rządowe (Cohen i in., 2002, s. 17-18), inne firmy poprzez alianse strategiczne lub fuzje i przejęcia (Ahuja, Katila, 2001, s. 197-220) oraz przedsiębiorców i młode firmy technologiczne typu startup, które ze względu na swoją specyfikę efektywnie przechwytują wiedzę (knowledge spillovers) $\mathrm{z}$ otoczenia i mogą następnie stać się metaźródłem wiedzy dla korporacji (Kohler, 2016, s. 347-357).

Do realizacji celu, jakim jest zwiększenie innowacyjności i konkurencyjności, jako potencjalne lokomotywy rozwoju najczęściej wskazywane są duże korporacje z uwagi na posiadane przez nie zasoby oraz dostęp do rynków. Natomiast jako otaczające firmy wskazywane są tzw. startupy technologiczne. Jednakże korporacje i startupy to zdecydowanie odmienne typy organizacji. Jedna strona ma to, czego drugiej brakuje: korporacja ma zasoby, skalę działania, doświadczenie i procedury niezbędne do skutecznego prowadzenia sprawdzonego modelu biznesowego (Koen $\mathrm{i}$ in., 2011, s. 52), ale ma też trudności w tworzeniu innowacyjnych modeli biznesowych (Hill, Rothaermel, 2003, s. 257). Startupy z kolei często nie dysponują zasobami (Alvarez, Barney, 2001, 139-144), jak również z uwagi na swoją nowość (newness) i mały rozmiar (smallness) narażone są na szereg innych barier rozwojowych (Brettel i in., 2007, s. 52); z drugiej jednak strony częstokroć mają one dużą tzw. zdolność innowacyjną, tj. obiecujące pomysły, zwinność organizacyjną, mniejszą awersję do ryzyka oraz aspiracje szybkiego wzrostu (Criscuolo i in., 2012, 319-333). Różnice między korporacjami a startupami stwarzają poważne wyzwania dla modelu ich interakcji, w którym odnoszone byłyby wzajemne korzyści. Korporacje są niedostępne dla startupów, różnice kulturowe prowadzą do nieporozumień, a różne prędkości i tryby działania często uniemożliwiają wspólne przedsięwzięcia (Kohler, 2016, s. 348). Jednakże w ciągu ostatnich lat korporacje podejmują wzmożone wysiłki zmierzające do nawiązania interakcji z ekosystemem startupowym. W swoim dążeniu do innowacyjności korporacje wypracowały wiele sposobów nawiązywania tego typu relacji. Sprawdzone modele, takie jak korporacyjne fundusze wysokiego ryzyka, są obecnie uzupełniane nowymi modelami, które $\mathrm{w}$ wielu przypadkach usprawniają ową współpracę (Weiblen, Chesbrough, 2015, s. 70-80).

Szereg badań wskazuje, że startupy mogą być źródłem szczególnie cennej i innowacyjnej wiedzy (Kortum, Lerner, 2000, s. 677). Co więcej, innowacyjne startupy mają pozytywny wpływ na wzrost gospodarczy, co w konsekwencji poprawia konkurencyjność (Bosma, Levie, 2010, s. 8) oraz zwiększa poziom zatrudnienia w całej gospodarce (Thurik, Wennekers, 2004, s. 141). 
Innowatorzy/naukowcy zakładają swoje firmy, kiedy dostrzegają potencjał większego zysku niż w wypadku pracy etatowej (Gans, Stern, 2003, s. 337). Dlatego można zaobserwować zakładanie silnie nasyconych wiedzą startupów technologicznych przeważnie, jeśli idea za nimi stojąca jest bardzo innowacyjna (Shane, 2001, s. 207). W konsekwencji wielu badaczy rekomenduje interakcje istniejących korporacji ze startupami w celu uzyskania dostępu do tych gniazd innowacji (Chesbrough, 2003; Gans, Stern, 2003, s. 342). Raport WEF (2018, s. 7) zawiera sześć proponowanych korzyści, dla których korporacje podejmują się interakcji ze startupami. Należą do nich: 1) dostęp do zewnętrznych innowacji, 2) bardziej innowacyjni dostawcy, 3) koncentracja na użytkowniku, 4) rozwój kultury przedsiębiorczej i „Zwinnej”, 5) pozostanie na bieżąco z rozwojem rynku, 6) nowe źródła dochodu i linie biznesowe.

Badacze wyróżniają szereg sposobów interakcji korporacji ze startupami. T. Weiblen i H. Chesbrough (2015) wyróżniają inwestycje kapitałowe, inkubację wewnętrzną (inside-out), inkubację zewnętrzną (ouside-in) oraz interakcję poprzez platformy, które łączą startupy z główną działalnością danej korporacji. Z kolei inni wskazują jeszcze na: jednorazowe wydarzenia, na przykład hackatony czy konkursy, współdzielenie zasobów, akwizycje, umowy o współpracy czy akceleracje (Bruneel i in., 2012; Kohler, 2016).

Wymienione w tabeli 1 rodzaje interakcji dużych firm ze startupami wskazują na wysokie zaangażowanie obu stron we współpracę; ukazują również, iż nie istnieje na tym etapie sprawdzona, jednolita ścieżka prowadzenia takiej współpracy. Praktyczna implementacja modelu konwoju zakłada m.in. wykorzystanie szeregu powyższych narzędzi w ramach spójnej struktury organizacyjnej w celu maksymalizacji korzyści dla obu stron i tym samym uzyskania szybszego rozwoju gospodarczego.

\section{Metoda badawcza}

Gównym celem niniejszego artykułu jest identyfikacja obecnego zaangażowania polskich korporacji we współpracę ze startupami, aby zweryfikować ich zdolność do odegrania roli "lokomotyw” w modelu konwoju. Aby odpowiedzieć na to pytanie, artykuł skupia się na perspektywie wybranych korporacji - potencjalnych lokomotyw w polskim systemie innowacji oraz w syntetyczny sposób zaznacza elementy polskiego systemu innowacyjności, które mają szczególny wpływ na możliwość zastosowania proponowanego modelu w praktyce.

Koncentracja na perspektywie korporacji pozwoli znaleźć odpowiedzi na pytania, które determinują gotowość danej korporacji do odegrania roli „lokomotywy” w modelu konwoju: jakie bariery powodują ograniczoną współpracę ze startupami; jak zorganizowane są kadry dla działań innowacyjnych; jak wygląda proces rozwoju projektów innowacyjnych; jakie narzędzia instytucjonalne są wykorzystywane przez korporacje do zwiększenia innowacyjności oraz jak mógłby wyglądać nowy, lepszy model wdrażania innowacji?

$\mathrm{W}$ prezentowanej pracy jako metodę badawczą przyjęto badania jakościowe - z uwagi na fakt, że odpowiedź na postawione pytania badawcze wymaga dogłębnego zrozumienia tematu. $\mathrm{W}$ związku $\mathrm{z}$ tym prezentowane badanie wykorzystuje analizę dokumentów źródłowych dotyczących polityki innowacyjnej Polski, jak również wnioski

Tabela 1. Sposoby interakcji korporacji ze startupami

\begin{tabular}{|c|c|c|}
\hline Sposób interakcji & Wskazania & Korzyści \\
\hline Inwestycje kapitałowe & $\begin{array}{l}\text { Potrzeba wzmocnienia potencjału } \\
\text { innowacyjnego firmy }\end{array}$ & $\begin{array}{l}\text { Wiedza o technologiach (Chesbrough, Tucci, 2004, s. 6), przewidywanie } \\
\text { kierunku rozwoju rynków (Benson, Ziedonis, 2009, s. 329), wzrost } \\
\text { produktywności wewnętrznych działów B+R (Maula i in., 2003), nauka na } \\
\text { porażkach i sukcesach startupów (Wadhwa, Kotha, 2006, s. 820) }\end{array}$ \\
\hline $\begin{array}{l}\text { Inkubacja wewnętrzna } \\
\text { (inside-out) }\end{array}$ & $\begin{array}{l}\text { Projekt innowacyjny odbiega od } \\
\text { głównej działalności korporacji; } \\
\text { wysokie ryzyko }\end{array}$ & $\begin{array}{l}\text { Możliwość powstania oddzielnych startupów, tzw. spin-off } \\
\text { (Weiblen, Chesbrough, 2015, s. 71) }\end{array}$ \\
\hline $\begin{array}{l}\text { Inkubacja zewnętrzna } \\
\text { (ouside-in) }\end{array}$ & $\begin{array}{l}\text { Brak gotowości startupu do } \\
\text { przejęcia poprzez niekompletny } \\
\text { zespół realizacyjny, nieukończony } \\
\text { produkt, brak weryfikacji } \\
\text { rynkowej czy niedoprecyzowany } \\
\text { model biznesowy }\end{array}$ & $\begin{array}{l}\text { Korporacje wykorzystują inkubatory w celu umożliwienia działania małym, } \\
\text { zwinnym zespołom w niezbiurokratyzowanym środowisku. Inkubatory } \\
\text { pozwalają również startupom uzyskać dostęp do zasobów danej korporacji, } \\
\text { m.in. możliwości lokalowych, produkcyjnych czy dystrybucyjnych, kapitału, } \\
\text { wiedzy eksperckiej i strategicznej, sieci relacji, otoczenia administracyjnego } \\
\text { (Gassmann, Becker, 2006, s. 22-26) }\end{array}$ \\
\hline $\begin{array}{l}\text { Interakcja poprzez } \\
\text { platformy }\end{array}$ & $\begin{array}{l}\text { Możliwość zaangażowania do } \\
\text { współpracy małych firm }\end{array}$ & $\begin{array}{l}\text { Tworzenie komplementarnych produktów, technologii czy usług, tworząc tym } \\
\text { samym nowy ekosystem (Gawer, Cusumano, 2014, s. 418) }\end{array}$ \\
\hline Akwizycja startupów & $\begin{array}{l}\text { Możliwość włączenia startupu do } \\
\text { korporacji }\end{array}$ & $\begin{array}{l}\text { Przyśpieszone wdrażanie nowych produktów, rozszerzenie dotychczasowej } \\
\text { oferty, wzmocnienie potencjału technologicznego (Puranam i in., 2006, s. 275) }\end{array}$ \\
\hline Akceleratory korporacyjne & $\begin{array}{l}\text { Możliwość nawiązania } \\
\text { relacji z dobrze rokującymi } \\
\text { przedsięwzięciami przed } \\
\text { potencjalną inwestycją kapitałową }\end{array}$ & $\begin{array}{l}\text { Czasowo ograniczone intensywne programy wsparcia adresowane do młodych } \\
\text { technologicznych firm na etapie skalowania przedsięwzięć w branżach } \\
\text { odpowiadającym branżom, w jakich operuje dana korporacja. Objęcie } \\
\text { stosunkowo niewielkich udziałów we wspieranych przedsięwzięciach w zamian } \\
\text { za stosunkowo małą inwestycję kapitałową (Fehder, Hochberg, 2014, s. 23) }\end{array}$ \\
\hline
\end{tabular}


z przeprowadzonych na potrzeby tegoż artykułu wywiadów z menedżerami korporacji. Całość danych empirycznych jest następnie poddana analizie zintegrowanej, która prowadzi do wyciągnięcia wniosków dla praktyki gospodarczej.

Spośród dostępnych metod zbierania danych jakościowych wybrano wywiady. Wybór takiej metody ma szereg zalet: jest ona skoncentrowana bezpośrednio na temacie badawczym, zapewnia zrozumienie kontekstu, umożliwia badaczowi kontrolę nad przebiegiem wywiadu i pozwala poznać informacje historyczne (Creswell, 2007, s. 140). W badaniu wykorzystany został wywiad częściowo ustrukturyzowany. Na potrzeby prezentowanego artykułu opracowano dwa scenariusze wywiadu: jeden mający charakter tematyczny i zawierający pytania badawcze oraz drugi $\mathrm{z}$ pytaniami, jakie mają być postawione respondentom, tj. dynamiczny; pytania są otwarte (patrz Aneks). Poza pytaniami głównymi są również pytania pomocnicze, które mają na celu pomóc $\mathrm{w}$ wywiadzie dla lepszego zrozumienia kontekstu i zapewnienia, iż wszystkie ważne kwestie zostaną poruszone w trakcie wywiadu (Kvale, Brinkmann, 2009, s. 138). Wywiady zostały przeprowadzone w ciągu jednego kwartału (trzeci kwartał 2017 r.); składały się z próby pięciu korporacji mających swoje siedziby w Polsce. Każdy wywiad trwał ok. 1,5 godziny i z każdego sporządzone zostały notatki według przygotowanego scenariusza.

Ustanowiony został zestaw kryteriów w celu określenia najbardziej odpowiednich respondentów. Po pierwsze, wybrano korporacje należące do grona dużych przedsiębiorstw, definiowanych poprzez zatrudnienie powyżej 250 pracowników, przychody powyżej 50 milionów euro rocznie i z sumą bilansową powyżej 43 milionów euro. Po drugie, badaniu poddano firmy, które mają siedzibę w Polsce. Po trzecie, wybrano firmy reprezentujące różne branże w celu analizy przedmiotowego tematu niezależnie od sektora. Wybrano pięć firm: KGHM Polska Miedź SA, Polskie Górnictwo Naftowe i Gazownictwo SA (PGNiG), Alior Bank SA, Grupa Lotos SA, Grupa Azoty SA. W ramach każdej firmy wybrano jednego rozmówcę na szczeblu średnim lub wyższym, zajmującego się innowacyjnością i/lub działalnością badawczo-rozwojową w firmie.

Odpowiedzi udzielone podczas wywiadów zostały poddane analizie, w tym również porównawczej, a wnioski zostały wykorzystane w celu sformułowania odpowiedzi na pytania badawcze. Wyniki przedstawione zostały $\mathrm{w}$ formie tabeli (tab. 2), która pozwala na porównanie odpowiedzi respondentów i strategii firm. Wybrana metoda badawcza posiada szereg ograniczeń, związanych przede wszystkim ze stosunkowo małą próbą badawczą. Niniejsze badania mają jednakże charakter pilotażowy i powinny zostać rozszerzone na większą próbę firm, aby pogłębić badania w przyszłości.

\section{Uwarunkowania polskiego systemu innowacji w kontekście modelu konwoju}

$\mathbf{P}$ olska należy do najmniej innowacyjnych krajów Europy (European Innovation Scoreboard 2017, s. 9). Analizując dostępne raporty i dokumenty źródłowe, stwierdzono, że jednym z kluczowych problemów jest szeroko pojęte niedofinansowanie działalności innowacyjnej w Polsce. To również niedofinansowanie $\mathrm{w}$ obszarze innowacyjności oraz niedojrzałość polskiego ekosystemu innowacji sprawiają, iż powiązania sieciowe na linii korporacje-startupy mogą okazać się kluczowe dla rozwoju innowacyjności w Polsce. Stopień rozwoju rynku kapitału wysokiego ryzyka w Polsce jest stosunkowo niski w stosunku do krajów UE. Poziom inwestycji funduszy private equity w relacji do PKB w Polsce wynosi przeciętnie 0,13\% PKB rocznie $\mathrm{i}$ jest mniej więcej trzy razy niższy niż w krajach skandynawskich. W latach 2010-2014 niższy poziom inwestycji $\mathrm{w}$ innowacyjne projekty niż w Polsce zanotowano tylko w Bułgarii, Czechach, Włoszech, Grecji i Rumunii. Narodowy System Innowacyjności (NSI) Polski nie potrafi produkować globalnie konkurencyjnych firm i tym samym nie wykorzystuje w pełni potencjału wiedzy ani technologii, jaka w Polsce istnieje. Mimo powstawania stosunkowo dużej liczby startupów technologicznych NSI Polski nie potrafi ich skalować globalnie. Występuje brak synchronizacji poszczególnych programów aktywnej polityki wspierania innowacyjności, brak zdefiniowanych metryk oraz brak monitorowania postępów w realizacji danych założeń (Zadura-Lichota, 2015). Luka finansowania innowacji dotyczy głównie mikrofirm i startupów. Brak odpowiedniego finansowania stanowi barierę innowacyjności dla 14\% przedsiębiorstw zatrudniających powyżej 250 osób, podczas gdy w grupie firm zatrudniających od 10 do 49 osób odsetek ten wynosi 22\%. Problem braku wystarczających zasobów jest najbardziej wyraźny w przypadku mikroprzedsiębiorstw i startupów. Badanie ankietowe PARP (Zadura-Lichota, 2015, s. 39) pokazuje, że brak wystarczających zasobów stanowi kluczową barierę innowacyjności dla małych firm.

\section{Perspektywa korporacji}

W tabeli 2 przedstawiono w sposób syntetyczny perspektywę korporacji na współpracę ze startupami. Patrząc na konkretne doświadczenia firm, część ta ma dostarczyć odpowiedzi na pytania badawcze oraz zaproponować wnioski dotyczące sposobów opracowania efektywniejszych narzędzi instytucjonalnych wspomagających innowacyjność poprzez współpracę korporacji ze startupami. Dodatkowo na tej podstawie dokonana zostanie ocena, czy i w jakim stopniu dana firma mogłaby pełnić funkcję lokomotywy w modelu konwoju.

Doświadczenia korporacji pokazują, iż w przypadku wystąpienia odmiennych celów oraz sposobów operowania istnieją znaczące bariery dla współpracy na linii korporacje - startupy. Korporacje - jako ustabilizowane biznesy - których celem jest systematyczna i efektywna realizacja bardzo ściśle zdefiniowanych modeli biznesowych, znacząco różnią się od startupów, których celem jest poszukiwanie skalowalnego modelu biznesowego, co wymaga elastyczności oraz eksperymentowania. Jeden z rozmówców podkreślił również, że „na tej linii współpracy często powstaje napięcie dot. znaczenia czasu - startupy muszą działać szybko (...), zaś duże korporacje mają długi proces decyzyjny”. Przeprowadzone wywiady 


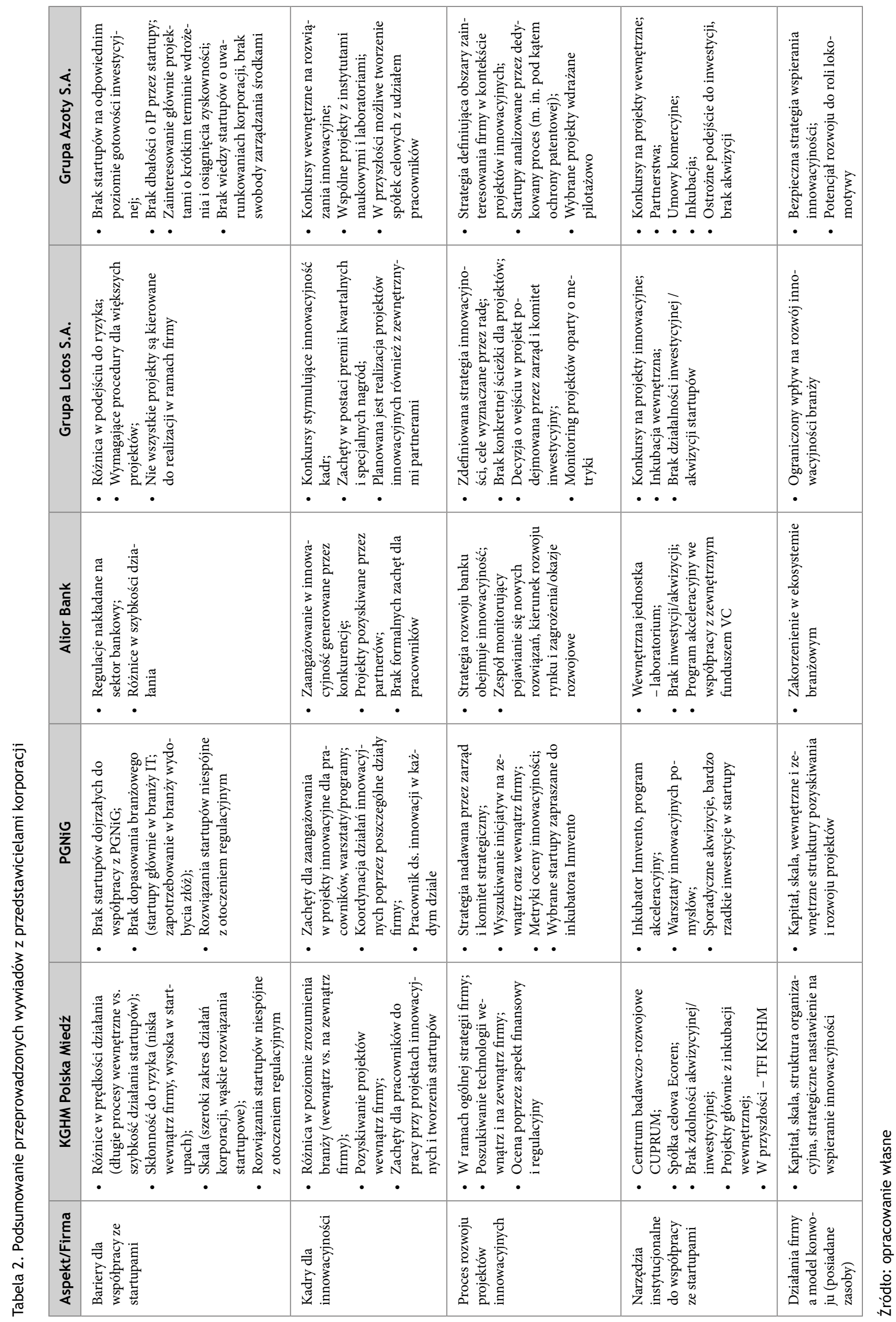


pokazują, iż zmienny charakter działalności startupów może mieć negatywny wpływ na stabilność korporacji. Duże firmy obawiają się, że eksperymenty prowadzone na ich kluczowych procesach produkcyjnych, głównych produktach czy usługach mogą przyczyniać się do zachwiania strumieni przychodów. Cel, jakim jest efektywność i skalowanie realizacji określonych modeli biznesowych, implikuje również duży zakres uprocesowienia działalności firmy, co w konsekwencji prowadzi do spowolnienia lub wręcz uniemożliwienia wdrażania ewentualnych zmian. Korporacje, operując na dużych rynkach, często są również poddane szeregowi regulacji prawnych, które dodatkowo zawężają możliwości elastycznego funkcjonowania. Z perspektywy korporacji większość startupów jest niedojrzała i niedofinansowana, a ich „butikowe” rozwiązania nie mają potencjału wsparcia ich konkurencyjności. Jeden $\mathrm{z}$ respondentów podsumował to, mówiąc: „Prawie każdy startup w naszej branży proponuje rozwiązania, które są nie do końca legalne. Startupy mają świetne pomysły na usprawnienie pracy, ale nie uwzględniają regulacji prawnych i norm bezpieczeństwa dot. wykorzystania kasków i kombinezonów, nie wiedzą na przykład, że rura musi być specyficznej grubości”. Konserwatyzm korporacji we współpracy ze startupami wynika również z faktu, iż startupy bardzo często nie posiadają wystarczającej wiedzy o rynkach, na jakich operują korporacje, nie znają ich uwarunkowań ani specyfiki, co powoduje, że rozwiązania, które oferują, są nieadekwatne do potrzeb. Jeden z rozmówców wspomniał, iż: „Branża wydobywcza jest mało popularna wśród startupów. My nie wpuszczamy nikogo na odwiert, przez co mało kto ma styczność z tym rodzajem działań”.

Badania wskazują również na koncentrację „do wewnątrz” w obszarze poszukiwania i wspierania pracowników, którzy mogą wygenerować innowacje w biznesie. Korporacje zazwyczaj opierają swoją aktywność innowacyjną na zasobach wewnętrznych i pracownikach - organizując konkursy na innowacyjne rozwiązania oraz starając się inkubować wewnętrzne projekty. Takie działania mają bardzo pozytywne skutki dla usprawniania istniejących procesów. Niemniej jednak nie pozwalają one na wdrażanie bardziej radykalnych innowacji, ponieważ taki model wyklucza integrację wiedzy z zewnątrz organizacji. Poza tym, zdaniem jednego z menedżerów, istnieją bariery w zwiększaniu wynagradzania pracowników chcących wdrażać innowacje, gdyż naprawdę wysokie premie mogłyby zaburzać hierarchię w firmie.

W kontekście procesu rozwoju projektów innowacyjnych, mimo stworzonych dokumentów strategicznych, które wskazują na fakt, iż korporacje zdają sobie sprawę z konieczności poprawy innowacyjności i konkurencyjności dla zachowania zyskowności, procesy i narzędzia wykorzystywane w tym obszarze są stosunkowo nierozwinięte, jak i nieskoordynowane ze sobą. Nieliczne próby współpracy z zewnętrznymi startupami przeważnie nie mają charakteru ciągłego. Współpraca $z$ nimi często nie jest mierzona, a korporacje nie wiedzą, w jaki sposób rozliczać startupy z działalności poza wskaźnikami finansowymi. Plany oraz cele wypracowane na poziomie strategicznym w niewielkim stopniu przekładają się na konkretne działania operacyjne.

Analiza rozwiązań instytucjonalnych stosowanych przez korporacje wskazuje, iż jedynym narzędziem wykorzystywanym szerzej we współpracy ze startupami jest inkubacja stosowana głównie na potrzeby wewnętrzne. Jest to atrakcyjna forma współpracy, ponieważ przeważnie nie wymaga ona od korporacji ponoszenia zbyt wysokiego ryzyka. Korporacjom brakuje jednak wiedzy na temat kierunku rozwoju rynków i w konsekwencji nie czują się one kompetentne, aby dokonywać inwestycji kapitałowych. W jednym $\mathrm{z}$ wywiadów respondent wyjaśnił: „Na chwilę obecną nie rozważamy CVC (ang. Corporate Venture Capital) ani żadnej formy inwestowania, z przyczyn strategicznych. Żeby robić CVC, trzeba mieć specyficzną wiedzę; (...) my angażujemy się w akcelerację, ale nie finansujemy firm.” Brak rozwiniętych startupów sprawia również, iż korporacje co do zasady nie przejmują zewnętrznych firm. Spośród analizowanych firm KGHM zastosowało ciekawą formę instytucjonalną współpracy ze startupami poprzez spółkę celową Ecoren, która może służyć za przykład dobrych praktyk w tym obszarze.

Analiza inicjatyw i działań związanych ze wspieraniem innowacyjności w perspektywie modelu konwoju ukazuje, że przeanalizowane firmy mogłyby pełnić funkcję lokomotyw - na różne sposoby i przy nieco odmiennych działaniach dostosowawczych. Ogólnym problemem wydaje się brak odpowiednich struktur organizacyjnych, które pozwoliłyby w sposób efektywny koordynować współpracę $\mathrm{z}$ otoczeniem $\mathrm{w}$ działaniach innowacyjnych.

\section{Wnioski oraz rekomendacje dla praktyki gospodarczej}

$\mathbf{Z}$ aprezentowana analiza perspektyw korporacji na współpracę ze startupami wskazuje na szereg wniosków. Przede wszystkim z analizy jasno wynika, iż zasoby przeznaczane przez polskie korporacje na rozwój innowacyjności oraz współpracę ze startupami są niewystarczające dla rozwoju innowacyjności. Mowa tutaj przede wszystkim o kapitale wysokiego ryzyka, ale również o kapitale ludzkim czy infrastrukturze. Ograniczona dostępność kapitału oraz innych zasobów wśród polskich firm innowacyjnych często uniemożliwia podjęcie działalności innowacyjnej. Brak zasobów wśród startupów technologicznych przekłada się z kolei na ich ograniczoną możliwość absorpcji wiedzy. Z drugiej strony korporacje, dostrzegając to, nie widzą zbytnich korzyści w interakcji z nimi, często szukając źródeł innowacyjności wewnątrz własnych organizacji - takie działanie ma jednak ograniczony potencjał. Mimo że korporacje dysponują odpowiednimi zasobami, nie mają narzędzi instytucjonalnych, jak również wypracowanych procesów dla efektywnego wykorzystania ich dla działalności innowacyjnej.

Kluczem do udanych innowacji prywatnych często było stworzenie odrębnej, w dużej mierze autonomicznej, jednostki organizacyjnej nieograniczanej przez korporacyjne zasady, na przykład spółka celowa Ecoren w KGHM 
stworzona przez pracowników. Jeden $\mathrm{z}$ menedżerów zapytany o to, czy warto wyodrębnić spółkę celową na potrzeby działań innowacyjnych, powiedział: „To jest jedyna droga. Wszyscy to robią, to jest jedyna sensowna metoda - spółka zależna kapitałowo, zapewniająca niezależność operacyjną i swobodę działania”. Inny rozmówca wskazał, iż jest to dobry kierunek, ale powinien być wspierany przez odpowiedni program rządowy. Co więcej, odrębność organizacyjna miała również swoje pozytywne implikacje w przypadku nielicznych inwestycji kapitałowych dokonywanych przez analizowane korporacje. Duże znaczenie miało też zachęcenie pracowników projektu do efektywnej pracy w długim terminie; często uzyskiwano to poprzez udziały realizatorów we własności danych przedsięwzięć. Ważne jest również to, iż tylko przedsięwzięcia, które miały wystarczające zasoby finansowe, przetrwały. Ostatecznie pozytywny wpływ miał również ścisły nadzór korporacji nad danymi przedsięwzięciami, który poza motywowaniem członków zespołów do pracy zapewniał również dostarczanie wiedzy.

W związku z przedstawionymi wnioskami szczególnego znaczenia nabiera rozwiązanie instytucjonalne wykorzystujące teoretyczny model konwoju, które, adresując ograniczenia wynikające $\mathrm{z}$ uwarunkowań NSI Polski, umożliwiłoby $\mathrm{z}$ jednej strony dostarczenie startupom niezbędnych zasobów bez ograniczania ich możliwości i elastyczności działania oraz z drugiej strony zagwarantowałoby korporacjom skorzystanie $\mathrm{z}$ wiedzy i potencjału tych małych firm technologicznych, nie narażając ich równocześnie na destabilizację głównych działalności. Tego typu mechanizm mógłby wspomóc również inkluzywność i adaptacyjność polskiej gospodarki, umożliwiając efektywniejsze wykorzystanie zasobów przy zachowaniu spójności celów na poziomie państwa, korporacji i startupu.

Po pierwsze, przeprowadzona analiza potwierdza, że rozwiązanie takie musiałoby zapewniać niezbędną autonomię startupom z powodu niekompatybilności sposobu operowania korporacji i startupów. W związku z tym owa struktura musi być odseparowana od właściwej struktury korporacji, ponieważ umiejscowienie jej wewnątrz narażałoby ją na konieczność dostosowywania się do procesów biurokratycznych mających na celu utrzymanie i poprawę efektywności działania dużej firmy, wykluczając elastyczność. Po drugie, rozwiązanie to powinno budować odpowiednie zachęty dla ludzi realizujących dane przedsięwzięcia. Ma to znaczenie zarówno dla tych tworzących startupy, jak i dla pracowników korporacji chcących realizować bardziej ryzykowne przedsięwzięcia. Innymi słowy, ludzie tworzący startupy powinni mieć na przykład udziały w danych przedsięwzięciach, które motywowałyby ich do ponoszenia ryzyka oraz do długoterminowego wysiłku w imię potencjalnych korzyści. W konsekwencji, po trzecie, struktura finansowania tych przedsięwzięć powinna charakteryzować się odrębnością od standardowych wydatków korporacji i nastawieniem na długi termin, $\mathrm{z}$ uwagi na fakt, że na efekty wydatkowanych środków najprawdopodobniej będzie trzeba czekać lata, co - jeśli pozostawione byłoby w głównej strukturze dużych spółek - skazywałoby ten mechanizm na ograniczone finansowanie. Po czwarte, pomimo dużej dozy autonomii nowa struktura musiałaby zapewniać korporacji matce mierzalne wskaźniki, na podstawie których mogłaby być rozliczana, ponieważ wskaźniki finansowe często nie są skutecznym narzędziem pomiaru na wczesnych etapach rozwoju przedsięwzięć technologicznych. W związku z tym konieczne byłoby opracowanie „księgowości innowacji”, mierzącej na przykład liczbę wykonanych eksperymentów rynkowych czy wzrost liczby użytkowników danych projektów.

Praktyczna struktura organizacyjna, która mogłaby spełnić wszystkie powyższe założenia, to oparte na teoretycznym modelu konwoju połączenie inkubatora/akceleratora, działu rozwoju biznesu oraz korporacyjnego funduszu VC. Taka kolonia innowacyjności, mimo strategicznej synchronizacji z tworzącą ją korporacją, musialaby być od niej fizycznie i proceduralnie odseparowana, musiałaby też mieć autonomiczny budżet, pozwalający jej na funkcjonowanie w długim terminie oraz dostęp do pozostałych zasobów korporacji, a do jej zadań należałoby inwestowanie $\mathrm{w}$ startupy, inkubowanie oraz akcelerowanie ich, jak również rekomendowanie korporacji potencjalnych celów akwizycyjnych. Dodatkowymi korzyściami dla korporacji z posiadania tego typu jednostki byłoby lepsze rozeznanie w rynku technologicznym, trendach i nowych modelach biznesowych na nim się pojawiających, potencjalny dostęp do strategicznych partnerstw, dostęp do przedsiębiorczej i innowacyjnej kadry oraz lepszy wizerunek jako pracodawca, jak również korzyści dla wizerunku korporacji.

Tabela 3. Podsumowanie propozycji nowej struktury organizacyjnej - model konwoju

\begin{tabular}{|l|l|}
\hline \multicolumn{1}{|c|}{ Sytuacja obecna } & \multicolumn{1}{|c|}{ Propozycja - model konwoju } \\
\hline $\begin{array}{l}\text { Niekompatybilność startupów i korporacji utrudnia } \\
\text { współpracę }\end{array}$ & $\begin{array}{l}\text { Dedykowana struktura organizacyjna neutralizująca problemy we współpracy korporacji } \\
\text { i startupów }\end{array}$ \\
\hline $\begin{array}{l}\text { Ograniczone zachęty dla zaangażowania } \\
\text { pracowników w działalność innowacyjną korporacji }\end{array}$ & Jasno ustanowiony system zachęt - np. udziały w realizowanych projektach innowacyjnych \\
\hline $\begin{array}{l}\text { Konserwatywne nastawienie do uruchamianych } \\
\text { projektów innowacyjnych }\end{array}$ & $\begin{array}{l}\text { W ramach wyodrębnionej struktury organizacyjnej możliwość ponoszenia większego ryzyka } \\
\text { oraz przyjęcia długoterminowej perspektywy }\end{array}$ \\
\hline $\begin{array}{l}\text { Rozliczanie projektów innowacyjnych wg ogólnie } \\
\text { przyjętych zasad księgowości }\end{array}$ & $\begin{array}{l}\text { Zastosowanie dedykowanej, rygorystycznej „księgowości innowacji” stosującej wskaźniki } \\
\text { odpowiednie dla innowacyjności, np. liczbę wykonanych eksperymentów rynkowych czy } \\
\text { liczbę użytkowników danych produktów }\end{array}$ \\
\hline
\end{tabular}




\section{Podsumowanie}

D odsumowując, należy stwierdzić, iż polskie korporacje dysponują wieloma $\mathrm{z}$ niezbędnych zasobów, które umożliwiłyby im pełnienie roli "lokomotyw" w modelu konwoju przy zastosowaniu szeregu zmian $\mathrm{w}$ formie prowadzenia współpracy ze startupami. Ostateczne potwierdzenie tego faktu wymaga jednak implementacji takiego rozwiązania w praktyce oraz weryfikacji realnych korzyści na przestrzeni czasu. Należy uznać ograniczenia badawcze wynikające z przyjętej metody, jak również z dynamicznego rozwoju obszaru poddanego badaniom. Rozszerzenie obecnych badań mogłoby pozwolić na ocenę $\mathrm{w}$ przyszłości efektywności rozwiązań rozwijanych obecnie przez polskie firmy. Ponadto analiza porównawcza działań firm polskich i zagranicznych pozwoliłaby zidentyfikować dobre praktyki w tym obszarze.

\section{Aneks}

Pytania tematyczne i dynamiczne

\section{mgr Wojciech Rokosz \\ Szkoła Główna Handlowa \\ Kolegium Gospodarki Światowej \\ e-mail: wr70611@doktorant.sgh.waw.pl}

\section{Przypis}

1) Praca naukowa finansowana ze środków budżetowych na naukę w latach 2012-2017 jako projekt badawczy w ramach programu Diamentowy Grant.

\section{Bibliografia}

[1] Ahuja G., Katila R. (2001), Technological Acquisitions and the innovation Performance of Acquiring Firms: A Longitudinal Study, „Strategic Management Journal”, Vol. 22, No. 3, pp. 197-220.

\begin{tabular}{|c|c|}
\hline Pytania tematyczne (badawcze) & Pytania dynamiczne (dla respondenta) \\
\hline \multirow{3}{*}{$\begin{array}{l}\text { Jakie bariery powodują ograniczoną } \\
\text { współpracę ze startupami? }\end{array}$} & $\begin{array}{l}\text { Jak są ustrukturyzowane wasze wysiłki w kierunku innowacyjności? Czy macie specjalną komórkę, która } \\
\text { się tym zajmuje? Jeśli nie, to jak zarządzacie swoimi działaniami? Jeśli oddzielna komórka, to czy ma ona } \\
\text { oddzielną lokalizację? }\end{array}$ \\
\hline & $\begin{array}{l}\text { Jak te działania innowacyjne funkcjonują w kontekście polityki firmowej, na przykład corocznego } \\
\text { budżetowania i innej korporacyjnej biurokracji? Jak pozyskiwany jest budżet na działania innowacyjne? }\end{array}$ \\
\hline & $\begin{array}{l}\text { W jaki sposób jednostka odpowiedzialna za innowacyjność odpowiada na potencjalne zastrzeżenia działu } \\
\text { finansowego, działu prawnego, regulacyjnego itp.? }\end{array}$ \\
\hline \multirow{4}{*}{$\begin{array}{l}\text { Jak zorganizowane są kadry dla działań } \\
\text { innowacyjnych? }\end{array}$} & Jakie jest nastawienie pracowników do innowacyjności? \\
\hline & Jak zorganizowane są kadry dla innowacyjności? Czy wykorzystujecie jakieś zachęty? \\
\hline & Czy obawiacie się, że przedsiębiorcze i innowacyjne osoby mogą odejść z waszej firmy? Dlaczego? \\
\hline & $\begin{array}{l}\text { Czy byłoby produktywne, jeśli ustrukturyzowano by płace dla pracowników innowacyjnych tak jak } \\
\text { w startupie? To znaczy na przykład pracownik oddaje połowę swojej pensji w zamian za udziały } \\
\text { w innowacyjnym przedsięwzięciu, nad którym pracuje? }\end{array}$ \\
\hline \multirow{5}{*}{$\begin{array}{l}\text { Jak wygląda proces rozwoju projektów } \\
\text { innowacyjnych? }\end{array}$} & Czy istnieje wizja albo hipoteza, która napędza i strukturyzuje działania innowacyjne? \\
\hline & Jak wybieracie projekty innowacyjne, które chcecie wspierać? \\
\hline & Czy wykorzystujecie metodę Lean Startup? Jaką funkcję ona pełni? \\
\hline & $\begin{array}{l}\text { Czy wykorzystujecie metryki? Jeśli tak, to jakie? Jak mierzycie postęp w działaniach innowacyjnych, } \\
\text { szczególnie w tych, które nie przynoszą jeszcze przychodu finansowego? }\end{array}$ \\
\hline & Jak oceniacie, czy produkt osiągnął tzw. Produkt/Market fit? \\
\hline \multirow{5}{*}{$\begin{array}{l}\text { Jakie narzędzia instytucjonalne } \\
\text { są wykorzystywane przez korporacje do } \\
\text { zwiększenia innowacyjności? Jak mógłby } \\
\text { wyglądać nowy lepszy model wdrażania } \\
\text { innowacji? }\end{array}$} & Czy akwizycje, inwestycje i inkubacja są pod jednym parasolem czy są to oddzielne jednostki? \\
\hline & Jaki procent działań innowacyjnych to inwestycje, jaki akwizycje, a jaki inkubacja? \\
\hline & $\begin{array}{l}\text { Jaki jest procent akwizycji vs. tzw. Aqiuhires (przejmowania firm głównie ze względu na pozyskanie } \\
\text { pracowników)? }\end{array}$ \\
\hline & Czy planujecie zwiększać skalę wysiłków innowacyjnych? Jeśli tak, to jak? \\
\hline & Czy rozważaliście wyodrębnienie wysiłków innowacyjnych do związanej firmy? \\
\hline
\end{tabular}

Źródto: opracowanie wtasne 
[2] Alvarez S.A., Barney J.B. (2001), How Entrepreneurial Firms can Benefit from Alliances with Large Partners, „Academy of Management Executive", Vol. 15, No. 1, pp. 139-148.

[3] Atkinson D., Ezell S. (2012), Innovation Economics - The Race for Global Advantage, Yale University Press.

[4] Benson D.F., Ziedonis R.H. (2009), Corporate Venture Capital as a Window on New Technologies: Implications for the Performance of Corporate Investors when Acquiring Star$t$-ups, „Organization Science”, Vol. 20, No. 2, pp. 329-351.

[5] Bitka K., Pietrasieński P., Rokosz W. (2017), Internationalization Support as the Integrating Axis of Innovation and Entrepreneurship Policies. Part 1 - Perspectives from National Innovation Systems in the European Union and European Bridge Organizations in Silicon Valley, „Przegląd Organizacji”, Nr 12, s. 5-12.

[6] Bitka K., Pietrasieński, P., Rokosz W. (2018), Internationalization Support as the Integrating Axis of Innovation and Entrepreneurship Policies. Part 2 - Perspective from Technology Startups, „Przegląd Organizacji”, Nr 1, s. 7-14.

[7] Bosma N., Levie J. (2010), Global Entrepreneurship Monitor, 2009 Executive Report, Global Entrepreneurship Research Association.

[8] Brettel M., Faaß K., Heinemann F. (2007), Controlling für innovative junge Unternehmen, „Controlling \& Management", Vol. 51, No. 3, pp. 52-67.

[9] Bruneel A.J., Ratinho T., Clarysse B., Groen A.J. (2012), The Evolution of Business Incubators: Comparing Demand and Supply of Business Incubation Services Across Different Incubator Generations, „Technovation”, Vol. 32, No. 2, pp. 110-121.

[10] Chesbrough H., Tucci Ch. (2004), Corporate Venture Capital in the Context of Corporate Innovation, DRUID Summer Conference 2004.

[11] Chesbrough H. (2003), Open Innovation: The New Imperative for Creating and Profiting from Technology, Harvard Business School Press, Boston.

[12] Cohen W.M., Goto A., Nagata A., Nelson R.R., Walsh J.P. (2002), R\&D Spillovers, Patents and the Incentives to Innovate in Japan and the United States, "Research Policy”, Vol. 31, No. 8, pp. 1349-1367.

[13] Creswell J.W. (2007), Qualitative Inquiry and Research Design, Sage, Thousand Oaks.

[14] Criscuolo P., Nicolaou N., Salter A. (2012), The Elixir (or Burden) of Youth? Exploring Differences in Innovation between Start-ups and Established Firms, „Research Policy", Vol. 41, No. 2, pp. 319-333.

[15] European Innovation Scoreboard, European Commission, 2017.

[16] Fehder D.C., Hochberg Y.V. (2014), Accelerators and the Regional Supply of Venture Capital Investment, SSRN Electronic Journal, https://papers.ssrn.com/sol3/papers. cfm?abstract_id=2518668.

[17] Fitjar D., Rodriguez-Pose A. (2011), Innovating in the Periphery: Firms, Values and Innovation in Southwest Norway, „European Planning Studies”, Vol. 19, No. 4, pp. 555-574.

[18] Florida R.L. (2004), The Rise of the Creative Class: And How It's Transforming Work, Leisure, Community and Everyday Life, Basic Books, New York.
[19] Gans J., Stern S. (2003), The Product Market and the Market for „Ideas”, „Research Policy”, Vol. 32, No. 2, pp. 333-350.

[20] Gassmann O., Becker B. (2006), Towards a Resource-based View of Corporate Incubators, „International Journal of Innovation Management”, Vol. 10, No. 1, pp. 19-45.

[21] Gawer A., Cusumano M. (2014), Industry Platforms and Ecosystem Innovation, „Journal of Product Innovation Management" Vol. 31, No. 3, pp. 417-433.

[22] Granovetter M. (1983), The Strength of Weak Ties: A Network Theory Revisited, „Sociological Theory”, Vol. 1, pp. 201-233.

[23] Henderson R. (1993), Underinvestment and Incompetence as Responses to Radical Innovation: Evidence from the Photolithographic Alignment Equipment Industry, „RAND Journal of Economics”, Vol. 24, No. 2, pp. 248-270.

[24] Hill C., Rothaermel F. (2003), The Performance of Incumbent Firms in the Face of Radical Technological Innovation, „The Academy of Management Review”, Vol. 28, No. 2, pp. 257-274.

[25] Koen P.A., Bertels H.M.J., Elsum I.R. (2011), The Three Faces of Business Model Innovation: Challenges for Established Firms, „Research Technology Management”, Vol. 54, No. 3, pp. 52-59.

[26] Kohler T. (2016), Corporate Accelerators: Building Bridges between Corporations and Start-ups, „Business Horizons", Vol. 59, No. 3, pp. 347-357.

[27] Kortum S., Lerner J. (2000), Assessing the Contribution of Venture Capital to Innovation, „RAND Journal of Economics”, Vol. 31, No. 4, pp. 674-692.

[28] Kvale S., Brinkmann S. (2009), InterViews: Learning the Craft of Qualitative Research Interviewing, Sage, Los Angeles.

[29] Laursen K., Salter A. (2006), Open for Innovation: The Role of Openness in Explaining Innovation Performance among U.K. Manufacturing Firms, "Strategic Management Journal", Vol. 27, No. 2, pp. 131-150.

[30] Lundvall B.-Å. (ed.), (1992), National Systems of Innovation. Towards a Theory of Innovation and Interactive Learning, Pinter Publisher, London.

[31] Maula M., Keil T., Zahra S. (2003), Corporate Venture Capital and Recognition of Technological Discontinuities, Working Paper, Helsinki University of Technology.

[32] Mensch G., Bertolin J.A. (2010), Convoy Model, Innovation Management, http://www.innovationmanagement. se/2010/12/08/convoy-model-the-dynamic-perspective-of-porterscluster-model.

[33] Porter M. (1990), The Competitive Advantage of Nations, The Free Press, New York.

[34] Puranam P., Singh H., Zollo M. (2006), Organizing for Innovation: Managing the Coordination-autonomy Dilemma in Technology Acquisitions, „Academy of Management Journal”, Vol. 49, No. 2, pp. 263-280.

[35] Saxenian A.L. (1994), Regional Advantage. Culture and Competition in Silicon Valley and Route 128, Harvard University Press, Cambridge.

[36] Saxenian A. (1990), Regional Networks and the Resurgence of Silicon Valley, „California Management Review”, Vol. 33, No. 1, pp. 89-112. 
[37] Schumpeter J. (1939), Business Cycles. A Theoretical, Historical and Statistical Analysis of the Capitalist Process, McGraw-Hill Book Company, New York.

[38] Shane S. (2001), Technological Opportunities and New Firm Creation, „Management Science”, Vol. 4, No. 2, pp. 205-220.

[39] Thurik R., Wennekers S. (2004), Entrepreneurship, Small Business and Economic Growth, "Journal of Small Business and Enterprise Development", Vol. 11, No. 1, pp. 140-149.

[40] Wadhwa A., Kotha S. (2006), Knowledge Creation through External Venturing: Evidence from the Telecommunications Equipment Manufacturing Industry, „The Academy of Management Journal”, Vol. 49, No. 4, pp. 819-835.

[41] Weiblen T., Chesbrough H. (2015), Engaging with Star$t$-ups to Enhance Corporate Innovation, „California Management Review", Vol. 57, pp. 66-90.

[42] Weresa M. (2012), Systemy innowacyjne we współczesnej gospodarce, Oficyna Wydawnicza Szkoły Głównej Handlowej w Warszawie, Warszawa.

[43] World Economic Forum (2018), Collaboration between Start-ups and Corporates. A Practical Guide for Mutual Understanding.

[44] Zadura-Lichota P., (2015), Innowacyjna przedsiębiorczość w Polsce. Odkryty i ukryty potencjat polskiej innowacyjności, PARP, Warszawa.
The Convoy Model as an Effective Mechanism for Knowledge Transfer from Innovation Hubs into the Polish Economy

\section{Summary}

The paper deals with the issue of interaction of corporations with start-ups. It analyzes the issue from the perspective of the corporation, taking into account the conditions of the Polish innovation system. The article presents tools that can be used by corporations to improve their competitiveness. It also indicates the benefits of using these to cooperate with start-ups to unleash the untapped potential of innovation. In the paper its author presents the results of original research on a group of Polish corporations, which verifies the effectiveness of their innovative activities carried out in cooperation with start-ups. Finally, the work presents the structure of the proposed new corporate structure, referred to as the innovation colony, which can effectively use these tools, based on the assumptions of the convoy model.

\section{Keywords}

institutional economics, knowledge transfer, open innovation, convoy model 